\title{
Effect of body composition of socially vulnerable elderly with diabetes and social support on self-care behavior
}

\author{
Sung, Ki-Wol ${ }^{1}$, Nam, Ji-Ran ${ }^{2}$, Kang, Hye-Seung ${ }^{2}$, Park, Ji-Hyeon ${ }^{3}$ and Park, Mi-Kyung ${ }^{4}$ \\ ${ }^{1}$ College of Nursing, Catholic University of Daegu, Korea \\ ${ }^{2}$ Department of Nursing, Gumi University, Gumi, Korea \\ ${ }^{3}$ Department of Nursing, Catholic Sangji College, Andong, Korea \\ ${ }^{4}$ College of Nursing, Yeungnam University College, Daegu, Korea
}

\begin{abstract}
Purpose: This study is to identify the effects of body composition and social support that affect the self-care behavior of the elderly with diabetes in the socially vulnerable group.

Methods: The subjects of this study were 120 health care recipients registered at 5 public health centers in D city and aged 65 or older who were diagnosed with diabetes by their doctors. The data were analyzed by t-test, one-way ANOVA, Pearson's correlation, and hierarchical multiple regression.

Results: The results of this study showed that the higher the BMI, the abdominal fat percentage and the body fat percentage, the lower the self-care behaviors and social support, and the higher the basic metabolism, the higher the self-care activities. In the final model, the total explanatory power of these variables was $56.3 \%$. Conclusions: Based on the results of this study, it is suggested that a self-care enhancement program considering the balanced body composition and high social support is developed and utilized in the socially vulnerable elderly with diabetes.
\end{abstract}

\section{Introduction}

The prevalence rate of diabetes in elderly people aged 65 years or older in Korea is $20.5 \%$. In particular, as the age increases, the prevalence rate also increases. After age 70 , the prevalence rate reaches $23.6 \%$, indicating that one in four elderly people have diabetes [1]. Considering the current situation, the prevalence rate of diabetes in Korea is expected to double to 5,910,000 in 2050 [2]. In addition, in Korea, the proportion of elderly people receiving basic living allowance is $29.9 \%$. The ratio of elderly recipients to total population is $6.0 \%$, which is the highest rate among other age groups [3]. The prevalence rate of diabetes in the vulnerable group including the basic livelihood recipient and the near poverty group was higher than the upper $25 \%$ of the income level. About $60 \%$ of people with diabetes in the vulnerable class perceive their health condition as bad and frail [4].

In diabetic patients in Korea, it has been reported that only $29.5 \%$ of patients with diabetes have less than $6.5 \%$ of glycated hemoglobin, which is the diabetes treatment criterion [5]. Diabetic patients of the vulnerable group have a low rate of adjustment to management goals, and the screening rate of diabetic complications is lower than that of normal diabetics [6]. The low rate of diabetes control has been a serious cause of increased rate of onset of diabetes-related complications and mortality rate [1]. The cerebrovascular/cardiovascular diseases caused by diabetes are 2-4 times higher than without diabetes. Diabetic care is critical because, with aging, diabetic complications begin to occur, such as hypertension (67\%), neuropathy (60-70\%), non-traumatic limb amputation (60\%), renal failure (44\%), blindness (28.5\%), etc [7].

However, diabetes complications can be prevented. Unlike other illnesses, prevention of complications is possible through appropriate self-management in daily life rather than depending entirely on medical staff [8]. Diabetes is a disease that must be accompanied by a change in self-management and personal lifestyle because it is difficult to prevent complications by a doctor's instructions or drugs alone. Given that average life expectancy and development of medical technology are likely to increase the duration of diabetes, proper self-care behavior in diabetic patients are essential for the prevention of dysfunction and various cardiovascular complications and for maintaining quality of life [9]. Because the increase in age and low-income levels are important factors that make it difficult to understand and use health information in everyday life [10], it is very important in nursing care to consider the age increase and low-income level for elderly patients with diabetes for exercising the self-care behavior.

For the elderly, the effects of decreased activity, decreased muscle mass, obesity, and inadequate diets have been pointed out as being factors decreasing tissue sensitivity to insulin and causing or aggravating elderly diabetes [11]. The World Health Organization (WHO) diagnoses obesity in the Asia-Pacific region with a body mass index (BMI) of $25 \mathrm{~kg} / \mathrm{m}^{2}$ or higher and overweight is diagnosed when the $\mathrm{BMI}$ is $23 \mathrm{~kg} / \mathrm{m}^{2}$ to $24.9 \mathrm{~kg} / \mathrm{m}^{2}$ [12]. As BMI increases, the frequency of cardiovascular disease, diabetes, and dyslipidemia that are associated with obesity increases and mortality rates increase. BMI is highly

Correspondence to: Nam, Ji-Ran, Department of Nursing, Gumi University 37, Yaeun-ro, Gumi-si, Gyeongsangbuk-do, South Korea, Tel: 82-54- 440-1307; Mob: 82-10-7515-2546; Fax: 82-54-440-1219; E-mail: sik4300@hanmail.net

Key words: aged, diabetes mellitus Type 2, social support, self care

Received: September 28, 2017; Accepted: October 27, 2017; Published: October 30,2017 
correlated with waist circumference, and each factor is independently a risk factor for diabetes [13]. And it was reported that BMI and waist circumference were higher in low-income and low-educated groups [14]. Furthermore, the American Diabetes Association [7] reported that those who are overweight $\left(\mathrm{BMI}>25 \mathrm{~kg} / \mathrm{m}^{2}\right)$ belonged to the high-risk group of diabetes, and the Korean Diabetes Association [15] suggests that being overweight $\left(\mathrm{BMI}>23 \mathrm{~kg} / \mathrm{m}^{2}\right)$ is a high-risk factor for diabetes. In addition, the elderly showed an increased risk of dyslipidemia due to weight gain and abdominal obesity due to poor health habits such as decreased activity as a result of aging. Managing body weight through self-care activities that correct lifestyle habits using diet and exercise therapy can be an important strategy for the prevention and treatment of diabetes [16].

Furthermore, patients with diabetes feel uncertainty about the future, anxiety, depression, sense of loss [17] and experience economic burden and social isolation. Unsatisfactory social support for diabetes leads to a lower quality of life for diabetic patients [18]. In particular, elderly people have the desire to depend on others to reduce their feeling of loneliness and isolation, and they learn lifestyle habits that affect the disease through social relations that can replace spousal or family support and through mutual encouragement [19]. Education on diabetes with peers can be a way to maintain the changes in lifestyle [20], and social support has been identified as a predictor to increase self-care behavior in diabetic patients [21]. In addition, if social support is decreased, the self-care of the individual becomes difficult and the physical function and emotional well-being are lowered [22]. In particular, low-income people do not have family or close friends to help them, and the diabetic self-care behavior level is low due to the misunderstanding that regular use of medication alone is enough to enable good management of diabetes [23].

The method of correcting weight gain, abdominal obesity and increase of dyslipidemia due to poor health habits as a result of aging is a strategy to prevent diabetes [17]. And social support for the elderly not only plays a protective role in the promotion of coping and adaptation to these problems, but also influences self-care behavior $[20,22]$. This study is to provide basic data for the development of the nursing intervention program for the self-care behavior of the elderly with diabetes in vulnerable groups by examining the effect of body composition and social support on self-care behavior of the socially vulnerable elderly with diabetes.

The purpose of this study is to identify the effects of body composition and social support that affect the self-care behavior of the elderly with diabetes in the socially vulnerable group. And the specific goals are as follows:

- To identify the body composition, social support and self-care behavior of the socially vulnerable elderly with diabetes

- To identify differences in self-care behavior according to general characteristics and health characteristics of the socially vulnerable elderly with diabetes

- To understand the correlation between the body composition/social support and self-care behavior in the socially vulnerable elderly with diabetes

- To understand the effect of the body composition and social support of the socially vulnerable elderly with diabetes on their selfcare behavior

\section{Methods}

\section{Study design}

This study is to investigate the effects of body composition and social support of the socially vulnerable elderly with diabetes on their self-care behavior.

\section{Setting and samples}

The subjects of this study are 120 recipients of Socially vulnerable elderly, registered in 5 public health centers in the city of $\mathrm{D}$, aged 65 or older and diagnosed with diabetes by their doctors. In addition, this study targeted the participants who voluntarily agreed in writing to participate in this study, understanding the contents of the questionnaire and the purpose of this study, receiving 24 points or higher for cognitive function (MMSE-K) and being able to communicate. As for the number of subjects, the study considered the dropout rate as well as the sample size at 98 as a result of the calculation with the two-sided test significance level $\alpha$ at 0.05 , multiple regression analysis effect size at 0.15 , and power $1-\beta$ at 0.90 in accordance with the $\mathrm{G}^{\star}$ Power 3.1 program. As a result, 120 copies were distributed. And, of these, 112 were finalized, except for 8 cases in which the answers to the questions were unsatisfactory or insufficient.

\section{Ethical considerations}

This study was conducted after the approval of research (IRB Protocol No; CUIRB-2014-0078-1) by the IRB of D University for the bioethics and safety of the subjects. And the guidelines of the IRB were followed during the study. Prior to the collection of data, the subjects were provided with explanation about the purpose of the study and that participation can be withdrawn at any time. In addition, written consent was signed to ensure the anonymity and autonomy of the subjects and that the collected data will be used for research purposes only. The subjects who participated in the study were given a small amount of compensation.

\section{Measurements}

\section{Body composition}

Body composition was measured using Inbody 230 (Biospace, Korea) using bio-electrical impedance. Body mass index (BMI) was classified into 'low body weight' $\left(\mathrm{BMI}<18.5 \mathrm{~kg} / \mathrm{m}^{2}\right)$, 'normal' $(18.5$ $\left.\mathrm{kg} / \mathrm{m}^{2} \leq \mathrm{BMI}<23 \mathrm{~kg} / \mathrm{m}^{2}\right)$, 'overweight' $\left(23 \mathrm{~kg} / \mathrm{m}^{2} \leq \mathrm{BMI}<25 \mathrm{~kg} / \mathrm{m}^{2}\right)$, and 'obesity' (BMI $\left.\geq 25 \mathrm{~kg} / \mathrm{m}^{2}\right)$. Body fat percentage refers to the proportion of fat in the body composition. Men and women were different in terms of body fat percentage, so the evaluation automatically classified from the Inbody results were used as is. For men, the standard is $10-20 \%$, the mild obesity is $20-25 \%$, and the obesity is over $25 \%$. For women, the standard is $18-28 \%$, the mild obesity is $28-33 \%$, and the obesity is over $33 \%$. The waist-hip ratio was calculated with the ratio of waist circumference to hip circumference. The standard range was classified as 0.80 to 0.90 for males and 0.75 to 0.85 for females. Males with waist circumference over $90 \mathrm{~cm}$ and females with over $85 \mathrm{~cm}$ were classified as obesity [14]. The standard range of basal metabolic rate is 1518 to 1774 Kcal for males and 1099 to $1261 \mathrm{Kcal}$ for females. For males, less than $1518 \mathrm{Kcal}$ is below standard and more than $1775 \mathrm{Kcal}$ is above standard. For females, less than $1099 \mathrm{Kcal}$ is below standard and more than 1262 Kcal is above standard.

\section{Social support}

Social support was measured with an adapted tool (adapted by Lim et al.) called MOS-SSS (Medical Outcomes Study Social Support 
Survey), which was originally developed by Sherbourne and Stewart. The tool consists of 19 questions of 4 sub-areas: 8 questions of emotional/informational support, 4 questions of material support, 3 questions of affectional support, and 4 questions of positive interaction. This is a 5-point Likert scale with possible scores ranging from 19 to 95. The higher the score, the higher the social support. Regarding the reliability of the tool when it was developed, Cronbach's alpha $=.97$. In the research of Lim et al. [24], Cronbach's alpha $=.86$. In this study, Cronbach's alpha $=.86$.

\section{Self-care behavior}

Self-care behavior was measured by the self-care behaviors measurement tool developed by Kim [25]. This tool consists of 20 questions: 5 questions of general health care, 7 questions of diet practice, 3 questions of medication, 2 questions of physical exercise, and 3 questions of glucose test. Each item is a 5-point scale, with possible scores ranging from 20 to 100 points. The higher the score, the higher the degree of self-care behavior. Cronbach's $\alpha=.85$ at the time of tool development. In this study, Cronbach's $\alpha=.88$.

\section{Data collection}

Data collection was conducted from May to June 2015. Five research assistants who had received preliminary guidance from the researchers explained the research objectives in advance, obtained written consent, measured the metabolic syndrome first and then conducted the survey. The questionnaire was distributed in the field and respondents were asked to respond in a self-recording format. For respondents with difficulty to write due to decreased vision, the researchers and the research assistants read the questionnaire personally so that respondents can provide answers. The time spent to measure the metabolic syndrome index and fill out the questionnaire was about 30 minutes.

\section{Data analysis}

The collected data were analyzed using IBM SPSS Win ver 20.0 as follows.

- The general characteristics, health characteristics, body composition, social support and self-care behavior of the subjects were calculated by frequency, percentage, mean, standard deviation, and range.

- One-way ANOVA and independent t-testing were analyzed for differences in self-care behavior according to general characteristics and health characteristics of the subjects.

- relationship between body composition, social support and selfcare behavior was analyzed by Pearson's Correlation Coefficient.

- Hierarchical regression analysis was used to identify factors influencing the self-care behavior of the subjects.

\section{Results}

\section{General characteristics of subjects}

As for the general characteristics of the subjects, $21.1 \%$ of the subjects were males and $77.2 \%$ were females. And as for the age, 7680 years old accounted for $34.8 \%$. In the case of religion, 'No Religion or Other' was the most with $33.9 \%$ followed by Christianity (29.5\%), Buddhism (25.0\%) and Catholicism (11.6\%). As for the educational level, 'Graduated Elementary School' was the most with $42.0 \%$. 56.3\% of the subjects were living alone, which was more than half. $86.6 \%$ of the subjects had a disease. $72.3 \%$ of the subjects exercised. Smoking was $8.9 \%$ and drinking was $15.2 \%$ (Table 1 ).

\section{Degree of body composition, social support and self-care behavior}

The mean BMI $\left(\mathrm{kg} / \mathrm{m}^{2}\right)$ of the subjects was $23.65 \pm 2.80$. The body fat percentage (\%) was $32.03 \pm 7.15$. Abdominal obesity rate (\%) was $.85 \pm .05$, which was somewhat higher than the median. The basal metabolic rate $(\mathrm{kcal})$ was $1299.96 \pm 135.84$, somewhat lower than the median. Social support was moderate at $62.96 \pm 16.53$ and affirmative support as the sub-factor was slightly lower at $2.94 \pm 1.09$. The selfcare behavior were $60.59 \pm 19.19$, which was somewhat higher than the median, and the medication as the sub-factor was $2.64 \pm 4.00$, indicating that the self-care behavior were the lowest (Table 2).

\section{Differences in self-care behavior according to general characteristics of subjects}

Self-care behavior according to general characteristics of the subjects were statistically significant in age $(\mathrm{F}=2.88, \mathrm{p}=.039)$, religion $(\mathrm{F}=3.31, p<.023)$, exercise $(\mathrm{t}=2.35, p=.020)$, and smoking $(\mathrm{t}=3.02$, $p=.003)$.

As a result of Scheffé post-hoc tests, for age, self-care behavior of 76-80 years old was significantly higher than 71-75 years old. As for religion, 'Christianity' was significantly higher in self-care activities than in Buddhism, no religion, and other religions. The self-care behavior was significantly higher in the exercise group than in the nonexercise group. In addition, the self-care behavior was significantly lower in the smoking group than non-smoking group (Table 1).

\section{Correlation between subject's body composition, social support, and self-care behavior}

The self-care behavior of the subjects showed a statistically significant negative correlation with body mass index $(r=-.33, p$ $<.001)$, abdominal fat ratio $(\mathrm{r}=-.47, p<.001)$, and body fat percentage $(\mathrm{r}=-.52, p<.001)$. And there was a statistically positive correlation with basal metabolic rate $(\mathrm{r}=.32, p=.001)$. The social support showed a statistically significant negative correlation with body mass index $(r$ $=-.29, p=.002)$, abdominal fat ratio $(\mathrm{r}=-.29, p=.002)$ and body fat percentage $(r=-.35, p<.001)$. In other words, the higher body mass index, abdominal fat percentage, and body fat percentage, the lower the self-care behavior. And the higher the basal metabolic rate, the higher the self-care behavior (Table 3).

\section{Factors affecting self-care behavior}

Hierarchical regression analysis was conducted in order to investigate the effect of the subject 's body composition and social support on their self-care behavior. From the general characteristics, age, exercise, smoking, and religion, which showed a statistical significance with the self-care behavior, were selected as major independent variables. Among them, exercise, smoking and religion were processed as variable number. In the first step of hierarchical regression analysis, social support was input. In the second step, the body mass index, abdominal fat percentage, body fat percentage, and basal metabolic rate were input. In the third step, age, exercise, smoking and religion were input. The results are shown in Table 4.

As a result of checking multi-collinearity of the multiple regression analysis in order to test assumptions about independent variables, the tolerance limits of the regression analysis ranged from 0.594 to 0.910 (over 0.1), and variation inflation factor (VIF) values ranged from 
Table 1. Differences of Self-care Behavior according to General Characteristics and Health Condition in Subjects ( $\mathrm{N}=112)$.

\begin{tabular}{|c|c|c|c|c|c|c|}
\hline Variables & Categories & n(\%) & Mean \pm S.D & $t / F$ & $\mathbf{p}$ & Scheffe \\
\hline \multirow{2}{*}{ Gender } & Male & $24(21.1)$ & $62.33 \pm 19.23$ & \multirow{2}{*}{-0.21} & \multirow{2}{*}{.836} & \\
\hline & Female & $88(77.2)$ & $63.13 \pm 15.84$ & & & \\
\hline \multirow{4}{*}{ Age(yr) } & $65-70 \mathrm{a}$ & $16(14.3)$ & $65.00 \pm 16.11$ & \multirow{4}{*}{2.88} & \multirow{4}{*}{.039} & \multirow{4}{*}{$\mathrm{b}<\mathrm{c}$} \\
\hline & $71-75 b$ & $24(21.4)$ & $58.00 \pm 16.54$ & & & \\
\hline & $76-80 \mathrm{c}$ & $39(34.8)$ & $68.33 \pm 15.42$ & & & \\
\hline & 81 or overd & $33(29.5)$ & $59.21 \pm 16.66$ & & & \\
\hline \multirow{4}{*}{ Religion } & Buddhista & $28(25.0)$ & $59.61 \pm 17.56$ & \multirow{4}{*}{3.31} & \multirow{4}{*}{.023} & \multirow{4}{*}{$\mathrm{a}, \mathrm{d}<\mathrm{c}$} \\
\hline & Catholicb & $13(11.6)$ & $64.46 \pm 15.71$ & & & \\
\hline & Protestantc & $33(29.5)$ & $69.88 \pm 13.76$ & & & \\
\hline & None or othersd & $38(33.9)$ & $58.89 \pm 19.80$ & & & \\
\hline \multirow{3}{*}{ Education level } & No formal educationa & $43(38.4)$ & $60.51 \pm 16.09$ & \multirow{3}{*}{1.31} & \multirow{3}{*}{.274} & \\
\hline & Elementary schoolb & $47(42.0)$ & $63.06 \pm 16.00$ & & & \\
\hline & $\begin{array}{c}\text { Middle schoolc or } \\
\text { abovec }\end{array}$ & $22(19.6)$ & $67.50 \pm 18.24$ & & & \\
\hline \multirow{4}{*}{ Living status } & $\begin{array}{l}\text { Married children and } \\
\text { spouse }\end{array}$ & $17(15.2)$ & $61.18 \pm 17.99$ & \multirow{4}{*}{0.65} & \multirow{4}{*}{.582} & \\
\hline & $\begin{array}{c}\text { Unmarried children or } \\
\text { relatives }\end{array}$ & $12(10.7)$ & $68.92 \pm 12.37$ & & & \\
\hline & Alone & $63(56.3)$ & $62.06 \pm 16.51$ & & & \\
\hline & As a couple & $20(17.9)$ & $63.70 \pm 17.84$ & & & \\
\hline \multirow{3}{*}{ BMI } & Under weight & $41(36.6)$ & $64.07 \pm 16.24$ & \multirow{3}{*}{0.31} & \multirow{3}{*}{.734} & \\
\hline & Normal weight & $5(4.5)$ & $58.20 \pm 23.64$ & & & \\
\hline & Over weight & $66(58.9)$ & $62.62 \pm 16.36$ & & & \\
\hline \multirow{2}{*}{ Diseases } & No & $97(86.6)$ & $69.98 \pm 15.14$ & \multirow{2}{*}{1.23} & \multirow{2}{*}{.235} & \\
\hline & Yes & $15(13.4)$ & $56.33 \pm 23.25$ & & & \\
\hline \multirow{2}{*}{ Exercise } & No & $81(72.3)$ & $65.19 \pm 16.67$ & \multirow{2}{*}{2.35} & \multirow{2}{*}{.020} & \\
\hline & Yes & $31(27.7)$ & $57.13 \pm 14.88$ & & & \\
\hline \multirow{2}{*}{ Smoking } & No & $10(8.9)$ & $48.40 \pm 16.53$ & \multirow{2}{*}{-3.02} & \multirow{2}{*}{.003} & \\
\hline & Yes & $102(91.1)$ & $64.38 \pm 15.91$ & & & \\
\hline \multirow{2}{*}{ Alchol } & No & $17(15.2)$ & $60.12 \pm 16.80$ & \multirow{2}{*}{-0.77} & 445 & \\
\hline & Yes & $95(84.8)$ & $63.46 \pm 16.53$ & & .445 & \\
\hline
\end{tabular}

Table 2. Degree of Body Composition, Social Support and Self-care Behavior in Subject (N=112).

\begin{tabular}{|c|c|c|c|c|}
\hline Category & Mean \pm S.D & $\begin{array}{c}\text { Item } \\
\text { Mean } \pm \text { S.D }\end{array}$ & Possible Range & Observed Range \\
\hline \multicolumn{5}{|l|}{ Body Composition } \\
\hline $\operatorname{BMI}\left(\mathrm{kg} / \mathrm{m}^{2}\right)$ & $23.65 \pm 2.80$ & & & $17.5-33.6$ \\
\hline Abdominal obesity rate & $0.85 \pm .05$ & & & $.71-1.01$ \\
\hline Body fat percentage (\%) & $32.03 \pm 7.15$ & & & $12.3-48.1$ \\
\hline Basal Metabolism(kcal) & $1299.96 \pm 135.84$ & & & $1054-1725$ \\
\hline Social support & $62.96 \pm 16.53$ & & $19-95$ & $33-95$ \\
\hline Emotional/informational support & & $3.06 \pm 1.12$ & $1-5$ & $1-5$ \\
\hline Material support & & $3.02 \pm 1.31$ & $1-5$ & $1-5$ \\
\hline Affirmative support & & $2.94 \pm 1.09$ & $1-5$ & $1-5$ \\
\hline Positive interaction & & $3.25 \pm 1.23$ & $1-5$ & $1-5$ \\
\hline Self-care behaviors & $60.59 \pm 19.19$ & & $20 \sim 100$ & $33 \sim 95$ \\
\hline General health care & & $2.56 \pm 0.89$ & $1-5$ & $1-5$ \\
\hline Diet practice & & $3.68 \pm 1.33$ & $1-5$ & $1-5$ \\
\hline Medication & & $2.64 \pm 4.00$ & $1-5$ & $1-5$ \\
\hline Physical exercise & & $3.53 \pm 1.41$ & $1-5$ & $1-5$ \\
\hline Glucose test & & $3.14 \pm 1.06$ & $1-5$ & $1-5$ \\
\hline
\end{tabular}

Table 3. Relationship among Body Composition, Social Support and Self-care Behavior in Subject $(\mathrm{N}=112)$.

\begin{tabular}{|c|c|c|}
\hline \multirow{2}{*}{ Variables } & Social support & Self-care behavior \\
\cline { 2 - 3 } & $\mathbf{r}(\boldsymbol{p})$ & $\mathbf{r}(\boldsymbol{p})$ \\
\hline BMI $\left(\mathrm{kg} / \mathrm{m}^{2}\right)$ & $-.29(.002)^{* *}$ & $-.33(<.001)^{* * *}$ \\
\hline Abdominal obesity rate & $-.29(.002)^{* *}$ & $-.47(<.001)^{* * *}$ \\
\hline Body fat percentage $(\%)$ & $-.35(<.001)^{* *}$ & $-.52(<.001)^{* *}$ \\
\hline Basal Metabolism $(\mathrm{kcal})$ & $.17(.076)$ & $.32(.001)^{* * *}$ \\
\hline
\end{tabular}

1.099 to 1.682 (under 10), indicating that there was no problem of multi-collinearity between independent variables. Also, as a result of checking the autocorrelation of the error, the Durbin-Watson statistic value was 1.429 , which was close to 2 , indicating no autocorrelation. As a result of the residual analysis, the standardized residuals ranged from -2.326 to 2.310 , satisfying the homoscedasticity, and the normal distribution of the error term was tested to confirm the suitability of the set model $(\mathrm{F}=14.01, p<.001)$. 
Table 4. Affecting Factors of Body Composition and Social Support on Self-Care Behaviors in Subject

\begin{tabular}{|c|c|c|c|c|c|c|c|}
\hline Step & Variables & B & SE & $\boldsymbol{\beta}$ & $t(p)$ & Adj. $R^{2}$ & $\mathbf{F}(p)$ \\
\hline \multirow[t]{2}{*}{1} & (Constant value) & 32.98 & 4.274 & & $7.716(<.001)$ & \multirow{2}{*}{.323} & \multirow{2}{*}{$54.06(<.001)$} \\
\hline & Social support & .50 & .067 & .57 & $7.353(<.001)$ & & \\
\hline \multirow[t]{6}{*}{2} & (Constant value) & 101.31 & 24.722 & & $4.098(<.001)$ & \multirow{6}{*}{.478} & \multirow{6}{*}{$21.29(<.001)$} \\
\hline & Social support & .34 & .065 & .40 & $5.287(<.001)$ & & \\
\hline & Body Mass Index (BMI) & -.40 & .455 & -.07 & $-.868(.388)$ & & \\
\hline & Abdominal fat rate & -62.72 & 24.780 & -.21 & $-2.531(.013)$ & & \\
\hline & Body fat percentage & -.51 & .198 & -.22 & $-2.552(.012)$ & & \\
\hline & Basic metabolism & .02 & .009 & .13 & $1.654(.101)$ & & \\
\hline \multirow[t]{12}{*}{3} & (Constant value) & 95.56 & 28.894 & & $3.307(.001)$ & \multirow{12}{*}{.563} & \multirow{12}{*}{$14.01(<.001)$} \\
\hline & Social support & .31 & .061 & .35 & $5.007(<.001)$ & & \\
\hline & Body Mass Index (BMI) & -.15 & .437 & -.03 & $-.333(.740)$ & & \\
\hline & Abdominal fat rate & -63.16 & 22.928 & -.21 & $-2.755(.007)$ & & \\
\hline & Body fat percentage & -.58 & .186 & -.25 & $-3.110(.002)$ & & \\
\hline & Basic metabolism & .01 & .009 & .09 & $1.189(.237)$ & & \\
\hline & Age & -.02 & .195 & -.01 & $-.089(.929)$ & & \\
\hline & Exercise" $^{*}$ & -3.61 & 2.420 & -.10 & $-1.492(.139)$ & & \\
\hline & Smoking* & 12.20 & 3.892 & .21 & $3.136(.002)$ & & \\
\hline & Religion $1^{*}$ & 1.97 & 3.863 & .04 & $.510(.611)$ & & \\
\hline & Religion $2^{*}$ & 7.79 & 2.929 & .22 & $2.660(.009)$ & & \\
\hline & Religion $3^{*}$ & -.07 & 2.829 & -.01 & $-.023(.982)$ & & \\
\hline
\end{tabular}

The result of applying social support to the model as the first step of the hierarchical regression analysis showed that the higher the social support, the greater the self-care behavior $(\beta=.57, p<.001)$, and the explanatory power of this model was $32.3 \%$. The result of inputting body mass index, abdominal fat percentage, body fat percentage, and basal metabolic rate as the second step of the hierarchical regression analysis, showed that the higher the abdominal fat rate, the lower the self-care behavior $(\beta=-.21, p=.013)$, and that the higher the body fat percentage, the lower the self-care behavior $(\beta=-.22, p=.012)$. Abdominal fat percentage and body fat percentage were further explained by $1.55 \%$, and the explanatory power of this model was $47.8 \%$. The result of inputting age, exercise, smoking, and religion as the third step of the hierarchical regression analysis, showed that the more the subjects smoke, the lower the self-care behavior $(\beta=-.21, p=.002)$. Self-care behavior was performed more by subjects with Christianity as a religion. The abdominal fat rate, which was identified as the explanatory variable in the second step, was not statistically significant with decreasing explanatory power $(\beta=-.21, p=.007)$. Smoking and religion were further explained by $8.5 \%$. In the final model, the total explanatory power of these variables was $56.3 \%$ (Table 4 ).

\section{Discussion}

This study was conducted to identify the impact of the body composition and social support of the socially vulnerable elderly with diabetes on their self-care behavior in order to provide basic data on the development of an effective self-care program for the socially vulnerable elderly with diabetes. The main results of this study are as follows.

The self-care behavior score of the subjects was 60.59 , which is higher than median. In a previous study [23] of low-income elderly diabetic patients, the level of self-care activities ranged from 0 to 112 with the average of 68.19. Direct comparison was difficult because the same tool was not used, but the result was similar to the results with a somewhat higher score. Among the sub factors of the self-care behavior, medication was 2.64, which was the lowest. In the case of low-income elderly diabetic patients, it is necessary to assess the diabetic education experience. In particular, drug-related education and information will need to be provided.
From the subjects' body composition, BMI $(\mathrm{kg} / \mathrm{m} 2)$ averaged 23.65 , indicating a high risk of diabetes. Body fat (\%) was $32.03 \%$ and abdominal fat percentage (\%) was $0.85 \%$, which was slightly higher than the median. Basal metabolic rate (kcal) was $1299.96 \mathrm{kcal}$, which was slightly lower than the median. Abdominal obesity, overweight, and obesity are the main causes of morbidity of diseases, such as diabetes, cardiovascular disease, and metabolic disorders, and of mortality, and are caused by complex actions of social, cultural, and environmental factors as well as genetic predisposition [26]. And this was similar to the report that the diabetic group has a significantly higher body mass index than the non-diabetic group [27]. Although previous studies are rarely done and direct comparisons are difficult, it is found that overweight and obesity trends are present in the socially vulnerable elderly with diabetes.

The social support of the subjects in this study was 62.96 , which was the medium. In this study, $56.3 \%$ of the subjects were living alone, which was more than half. As a result, affirmative support, the subfactor of social support, seems to be somewhat low at 2.94. Direct comparison is difficult because the same research tool was not used. However, the results were similar to those of the study of social support and self-care of diabetic patients, which suggested that physical function and emotional well-being are lowered and patients have a difficulty in self-care as social support decreases [22]. In particular, in the case of low-income patients, it is necessary to provide education and nursing intervention program with reinforced social support based on a previous study that reported that diabetic patients had low levels of self-care behavior without any family or anyone to help them [23].

In this study, the hierarchical regression analysis was conducted in order to investigate the effect of the subject's body composition and social support on self-care behavior. In the first step of hierarchical regression analysis, social support was input. In the second step, the body mass index, abdominal fat percentage, body fat percentage, and basal metabolic rate were input. In the third step, age, exercise, smoking and religion were input. The result of applying social support to the model as the first step of the hierarchical regression analysis, showed that the higher the social support, the greater the self-care behavior, and the explanatory power of this model was $32.3 \%$. The 
result of inputting body mass index, abdominal fat percentage, body fat percentage, and basal metabolic rate, showed that the higher the abdominal fat rate, the lower the self-care behavior, and that the higher the body fat percentage, the lower the self-care behavior. Such results support the study result [16] that the method of correcting weight gain, abdominal obesity and increase of dyslipidemia due to poor health habits as a result of aging can be a strategy to prevent and treat diabetes. The results also support that the results of previous studies $[22,23]$ that social support for the elderly not only plays a protective role in promotion of coping and adaptation to these problems, but also influences self-care behavior.

In addition, the result of inputting age, exercise, smoking, and religion as the third step of the hierarchical regression analysis, showed that the more the subjects smoke, the lower the self-care behavior. Selfcare behavior was performed more by subjects with Christianity as a religion. The total explanatory power of these variables was $56.3 \%$. The previous study showed that the general characteristics that affect the self-care of the elderly were economic level, age, social activity, spouse, and exercise [8,9], supporting some of the results of this study. Restraint from smoking is recommended as smoking increases the risk of developing diabetes and complications through mechanisms such as lipid metabolism abnormality [28] and increased insulin resistance [29] depending on the cumulative smoking amount.

There is a lack of precedent studies on body composition, social support and self-care behavior of the socially vulnerable elderly with diabetes, making active comparison to be difficult. However, the balanced body composition and high social support of the socially vulnerable elderly with diabetes have improved the patients' self-care behavior. Therefore, it can be used as a strategy for promoting self-care behavior.

A benefit of this study is that it has confirmed the influencing factors of self-care behavior according to body composition and social support of diabetic elderly people in vulnerable classes. However, the study also shows limitations in that the results cannot be generalized, as the subjects were not randomly selected.

\section{Conclusion}

This study was carried out to investigate the effects of body composition and social support of the socially vulnerable elderly with diabetes in accordance with their self-care behavior. The result of the study has shown that the higher body mass index, abdominal fat percentage and body fat percentage, the lower the self-care behavior, and that the higher the basal metabolic rate, the higher the self-care behavior.

Based on the results of this study, it is suggested that a self-care enhancement program considering the balanced body composition and high social support is developed and utilized in the socially vulnerable elderly with diabetes.

\section{Research funding}

This research was supported by Basic Science Research Program through the National Research Foundation of Korea (NRF) funded by the Ministry of Science, ICT \& Future Planning (No.2014051906).

\section{References}

1. Statistics Korea. 2012 Korea Health Statistics [Internet]. Seoul: Ministry of Health and Welfare \& Korea Centers for Disease Control \&Prevention 2013.
2. Korea Centers for Disease Control and Prevention (2015). Current status and need for a korean diabetes prevention study. Public health weakly report. 8: 746-753.

3. Ministry for Health and Welfare (2014) 2013 Recipient of the national basic status.

4. Kim HM, Choi YH (2011) Factors affecting depression in elderly vulnerable people living alone. J Korean Acad Community Health Nurs 22: 355-364.

5. Korean Diabetes Association (2012) Diabetes fact sheet in Korea2012 [Internet] Seoul: Korean Diabetes Association.

6. Brooks M, Bustos I, Lyter J, Stevenson M (2010) The correlation between diabetes mellitus type II and low socioeconomic communities. Poster session presented at Stanford medical youth science program 2010 summer residential program graduation ceremonies.

7. Basevi V, Di Mario S, Morciano C, Nonino F, Magrini N (2011) Comment on: American Diabetes Association. Standards of medical care in diabetes-2011. Diabetes Care 2011;34(Suppl. 1):S11-S61. Diabetes Care 34: e53. [Crossref]

8. Choi GA, Jang SM, Nam HW (2008) Current status of self-management and barriers in elderly diabetic patient. Korean Diabetes J 32: 280-289.

9. Kang KJ, Yu SJ, Seo HM, Yu M, Park MS, et al. (2012) Jang HC. Factors Influencing self-management behavior for patients with type 2 diabetes: comparison of difference between the elderly and adults. J Korean Biol Nurs Sci 14: 112-121.

10. Lee TH, Kang SJ (2008) Health literacy in the korean elderly and influencing factors: By focusing on sociology of population. J Korean Gerontological Society 28: 847-863.

11. Nam HW (2007) Clinical features of elderly diabetic patients. Korean Clin Diabetes J 8: 11-15.

12. World Health Organization (2016) BMI classification [Internet].Switzerland: World Health Organization.

13. Dalton M, Cameron AJ, Zimmet PZ, Shaw JE, Jolley D, et al. (2003) Waist circumference, waist-hip ratio and body mass index and their correlation with cardiovascular disease risk factors in Australian adults. J Intern Med 254: 555-563.

14. Ball K, Berch DB, Helmers KF, Jobe JB, Leveck MD, et al. (2002) Effects of cognitive training Interventions with older adults: a randomized controlled trial. JAMA 288: 2271-2281.

15. Task Force Team for Basic Statistical Study of Korean Diabetes Mellitus. Report of task force team for basic statistical study of korean diabetes mellitus: diabetes in Korea 2007. 1st ed. Seoul: Goldfishery.

16. Walker KZ, O’Dea K, Gomez M, Girgis S, Colagiuri R (2010) Diet and exercise in the prevention of diabetes. J Hum Nutr Diet 23: 344-352. [Crossref]

17. Lustman PJ, Clouse RE, Griffith LS, Carney RM, Freedland KE (1997) Screening for depression in diabetes using the Beck Depression Inventory. Psychosom Med 59: 2431. [Crossref]

18. Bourdel-Marchasson I, Druet C, Helmer C, Eschwege E, Lecomte P, et al. (2013) Correlates of health-related quality of life in French people with type 2 diabetes. Diabetes Res Clin Pract 101: 226-235.

19. Kim HG, Lee KJ (2008) A survey on elders experience in and preference for a mentoring program. J Korean Acad Community Health Nurs 19: 554-563.

20. Barrera MJ, Glasgow RE, Mckay HG, Boles SM, Feil EG (2002) Do Internet-based support interventions change perceptions of social support?: An experimental trial of approaches for supporting diabetes self-management. Am J Community Psychol 30: 637-654.

21. Goz F, Karaoz S, Goz M, Ekiz S, Centin I (2007) Effect of the Diabetes Patients Perceived Social Support on Their Quality-of-life. J Clin Nurs 16: 1353-1360.

22. Miller CK, Davis MS (2005) The influential role of social support in diabetes management. Topics in Clinical Nutrition 20: 157-165.

23. Lim JS (2011) Diabetes awareness survey and diet survey in low-income diabetes patients [master's thesis]. [Seoul]: Ewha Womans University.

24. Lim MK, Shin YS, Yoo WS, Yang BM (2003) Social support and self-rated health status in a low income neighborhood of Seoul, Korea. Korean J Prev Med 36: 54-62.

25. Kim YO (1997) A hypothesized model for self-care behavior in diabetic patients: based on stress-coping model [dissertation]. [Seoul]: Yeonsei University. 
26. Ha CH, Ha S, So WY (2012) Effects of a 12-week combined exercise training program on the body composition, physical fitness levels, and metabolic syndrome profiles of obese women. J Korean Pubilc Health Nurs 26: 417-427.

27. Brach JS, Talkowski JB, Strotmeyer ES, Newman AB (2008) Diabetes mellitus and gait dysfunction: possible explanatory factors. Phys Ther 88: 1365-1374.
28. Chiolero A, Faeh D, Paccaud F, Cornuz J (2008) Consequences of smoking for body weight, body fat distribution, and insulin resistance. Am J Clin Nutr 87: 801-809. [Crossref]

29. Calo WA, Ortiz AP, Suárez E, Guzmán M, Pérez CM, et al. (2013) Association of cigarette smoking and metabolic syndrome in a Puerto Rican adult population. $J$ Immigr Minor Health 15: 810-816.

Copyright: $\odot 2017 \mathrm{Ki}-$ Wol S. This is an open-access article distributed under the terms of the Creative Commons Attribution License, which permits unrestricted use, distribution, and reproduction in any medium, provided the original author and source are credited. 